\title{
INFLUENCE OF SHIELDING GAS ON GEOMETRICAL QUALITY OF WAAM TECHNOLOGY
}

\author{
Tomas GURCIK, Karel KOVANDA, Pavel ROHAN \\ CTU in Prague - Czech Technical University of Prague, Faculty of Mechanical Engineering, Prague, Czech \\ Republic, EU, Tomas.Gurcik@fs.cvut.cz
}

https://doi.org/10.37904/metal.2019.871

\begin{abstract}
Welding technology is not currently merely a technology for joining materials. With the development of additive manufacturing, welding can also be used as a technology to produce complex components. WAAM together with 3D metal printing are the basic technologies used for additive production. WAAM (Wire and Arc Additive Manufacturing) technology is characterized by cladding weld passes into final shape of mechanical part. The WAAM process is characterized by several variables, among others the MIG/MAG protective gas shield effects. The aim of this paper is to evaluate the influence of individual components of protective gases used for welding the whole structure. Especially it regards of Argon, Carbon dioxide, Oxygen and Helium according to the resulting component geometry and to the efficiency of the welding process. Thanks to the results obtained, a suitable shielding gas can be better determined by reducing the heat input to the material during welding especially reducing or eliminating content of carbon dioxide or helium.
\end{abstract}

Keywords: WAAM, additive manufacturing, shielding gases, robotic welding, geometrical quality

\section{INTRODUCTION}

Additive manufacturing is increasingly used in engineering practice to create parts of complex shapes. Among the best-known additive manufacturing technologies a3D sintering of metal powder using laser beam and WAAM (Wire and Arc Additive Manufacturing) technology using welding. 3D printing is used to create small parts with very difficult internal geometry that cannot be manufactured using conventional production methods. WAAM is used for the rapid production of relatively large components with the main purpose of avoiding large waste material such as those arising from the machining of large semi-finished products.

Since the welding process is defined by many variables affecting the stability of WAAM, this work deals with one of them - the effect of shielding gases used.

\section{ADDITIVE MANUFACTURING}

The global 3D printing metal market size was valued at USD 334.4 million in 2017. It is expected to witness a compound annual growth of $31.8 \%$ from 2017 to 2025 . We can notice that the largest industry in additive manufacturing is the aerospace and defence, automotive and medical industries. Remember that additive technology is not only classic 3D printing that we know well. Before characterizing WAAM technology, it is advisable to classify this alternative additive technology [1].

Generally, additive manufacturing technologies are classified according to several criteria. In particular, it is possible to divide the additive production according to the type of additive used. In technologies where the heat

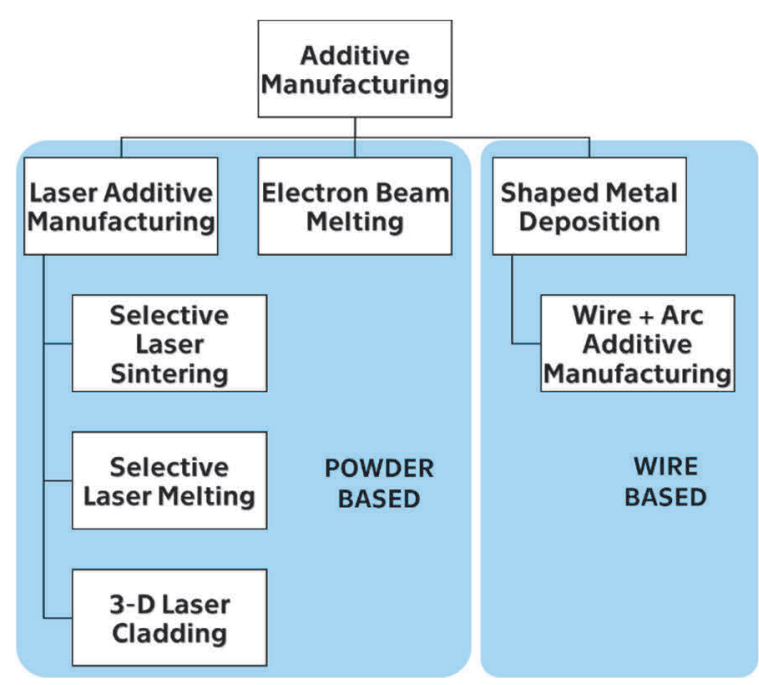

Figure 1 Classification of additive technologies according to the use of the heat source and the type of additive material 
source is a laser beam or an electron beam, the additive material is used in the form of a metal powder. Whereas in a technology using as a source of thermal energy the electric arc is an additive material in the form of a conventional welding wire. This technology is called WAAM, which stands for Wire and Arc Additive Manufacturing - see Figure 1.

3D metal printing works on the principle of sintering the additive material as a metal powder. With this method it is possible to create extremely geometrically complex structures without any further modifications. However, the disadvantage of this technology is the cost of manufacturing equipment and additive material with long production times.

WAAM combines an electric arc as a heat source and filler material in the form of wire for welding and cladding individual weld passes so as to ultimately achieve the closest shape of produced components. As classical additive technology in manufacturing we consider 3D printing or otherwise SLS (Selective Laser Sintering), when the laser beam is sintered material that is in powder form to a layer thickness of about $0.1 \mathrm{~mm}$. WAAM technology is considered an alternative additive technology as it is based on the classic SLS principle, but its investment and operational demands are more favourable - see Figure 2 ..

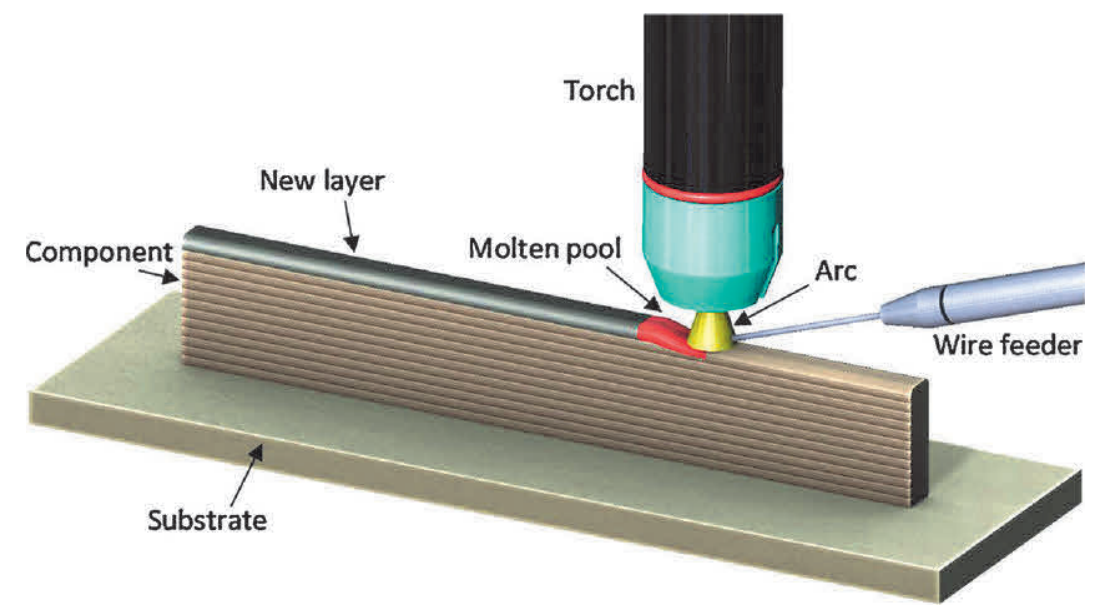

Figure 2 Illustration of the WAAM process using TIG technology [2]

WAAM technology uses welding technology to lay the individual weld passes up to the final shape. For WAAM conventional welding robots and CNC gantry machine installed with a welding torch can be used, which moves according to the programmed path. This technology, rather than small components, can effectively produce large machine components. Currently, WAAM is being developed for use in the aerospace industry to reduce BTF (Buy to Fly) ratio. The idea is to reduce the amount of waste material generated during production and thereby reduce aircraft sales prices [3].

$B T F=\frac{\text { raw material used for a component }}{\text { weight of the component itself }}$

WAAM is far from being used for small and detailed components in terms of part size. Rather, it is used for components that are additive in terms of technology simple. WAAM is supposed to be used for very large parts, especially for the radical reduction of waste material, as these are lightweight or hollow profiles, parts with reinforcements, etc. It is no exception that two robots work on such large parts. Metal powdered laser technologies are limited by their application speed, and especially the size of the workspace. While WAAM is also speed-limited to maintain quality, speed is higher than other additive technologies. As far as the size of the workspace is concerned, WAAM is very limited, as if the workspace is not enough for the robot it can be set on a linear travel. This is primarily why WAAM will not be used on small aircraft engine elements, but on a large part of the aircraft skeleton - see Figure 3. 


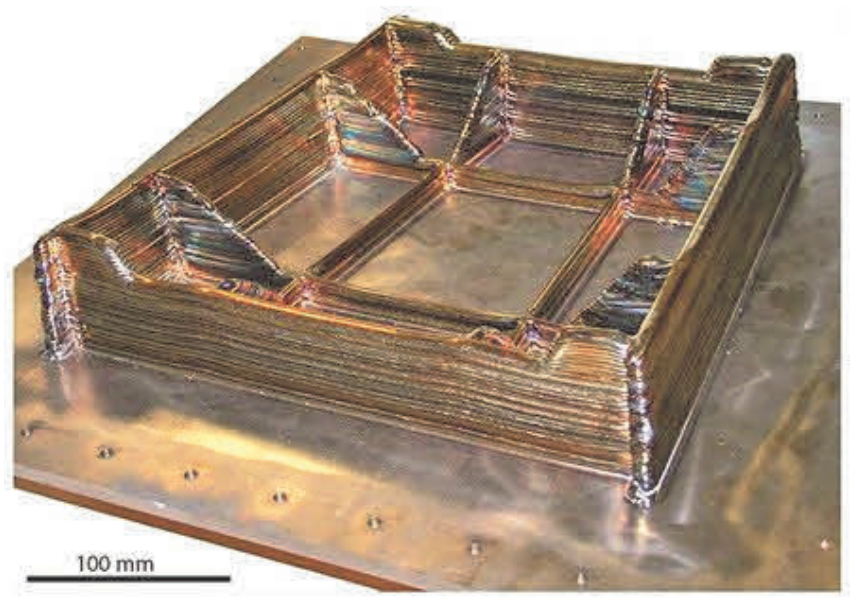

Figure 3 Prototypal part of the $24 \mathrm{~kg}$ chassis of Bombardier made from Ti-6AI-4V made by WAAM [4]

\section{SHIELDING GASES FOR WELDING}

There are a lot of variables in WAAM that need to be constant to ensure WAAM process stability like in the Figure 4. In this experiment, it is discussing one of the variables that affect welding technology.

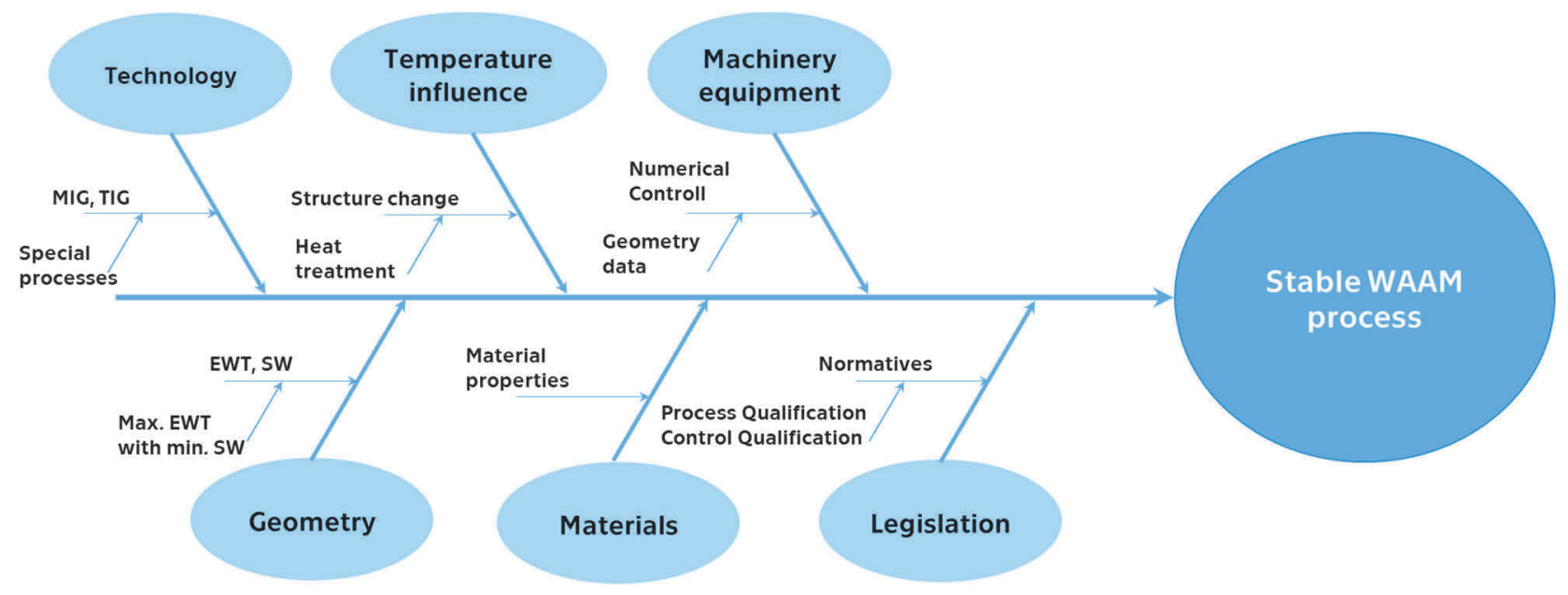

Figure 4 Diagram of variables at WAAM technology

The main variables in welding technology are welding parameters such as welding current, voltage and wire feed speed. Furthermore, it is welding process that can be a short circuit, impulse or special digitally controlled process. Another variable may be a shielding gas and of course additive (or we can say filler) material. In this experiment the focus is on influence of shielding gas used for WAAM on geometric quality of welded piece.

The main role of shielding gas in welding is to prevent the surrounding atmosphere from entering the weld pool, maintaining arc stability and protecting the electrode. Shielding gases also have a major impact on the type of weld metal transfer, thermal energy transfer, welding speed, etc.

In the experiment, the effects of mixture gases composed of different contents of argon, carbon dioxide, oxygen and helium. Thermal conductivity of each gas is shown in the picture Figure $\mathbf{5}$.

Argon (Ar) is single atomic gas, has low thermal conductivity and low ionization potential, does not form any element of chemical compound.

Carbon dioxide $\left(\mathrm{CO}_{2}\right)$ has a high thermal conductivity and thus causes a high heat transfer to the weld pool. 


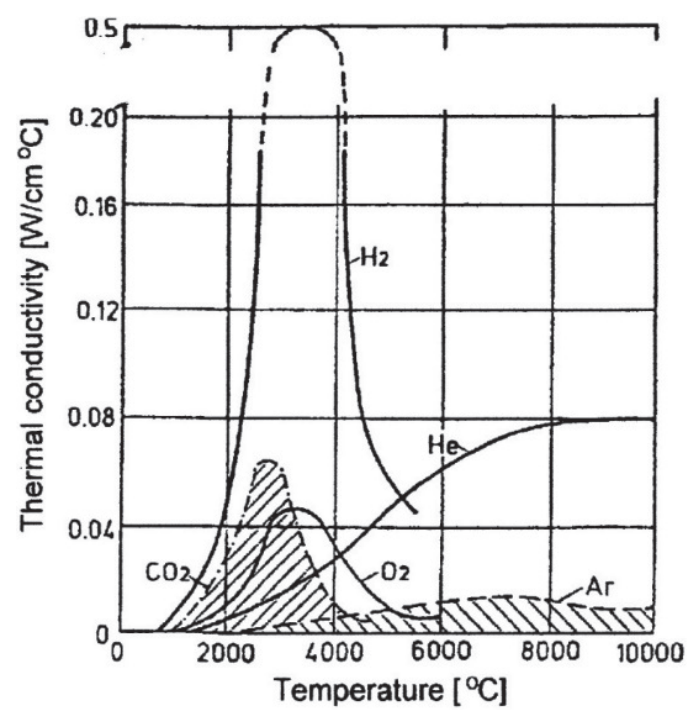

Figure 5 Thermal conductivity of gases as a function of temperature [5]

Oxygen $\left(\mathrm{O}_{2}\right)$ greatly increases the fluidity of the weld pool and increases its surface tension, which improves the degassing of the weld pool.

Helium $(\mathrm{He})$ is very light single atomic gas, because of the low value of density, a higher gas flow is needed, and it has higher thermal conductivity than $\mathrm{CO}_{2}$.

\section{EXPERIMENT}

The objective of the experiment is to weld the structures using a programmed circular path with a total of 50 layers. For each continuously welded structure shielding gas was used, but with a different composition each time. The wire feed speed parameter was constantly set for each process of cladding. CMT was used as a welding process to reduce the heat input during the welding process.

The main part of the experiment took place in the inter-faculty Laboratory of Welding Technologies situated at Department of Manufacturing Technology CTU in Prague, which has, among other things, a robotic workplace for arc welding. This workplace contains the universal 6-axis FANUC Arc Mate 100iC robot with a maximum reach of $1420 \mathrm{~mm}$ and with a one-axis positioner FANUC P250.

The welding parameters were designed according to recommendations by Kolarik [6], the welding wire feed rate of $2.4 \mathrm{~m} \cdot \mathrm{min}^{-1}$ and the shielding gas flow of $15 \mathrm{I} \cdot \mathrm{min}^{-1}$. Welding speed was $35 \mathrm{~cm}$. min-1. As additive material was used G 423 C G3 Si1 with diameter of $1 \mathrm{~mm}$. Maxx® shielding gases with the composition given in Table 1 were used.

Table 1 Composition of used shielding gases [7]

\begin{tabular}{|c|c|c|c|c|}
\hline \multirow[b]{2}{*}{ Maxx Gases $^{\circledR}$} & \multicolumn{4}{|c|}{ Composition in \% } \\
\hline & $\mathrm{Ar}$ & $\mathrm{CO}_{2}$ & $\mathrm{O}_{2}$ & $\mathrm{He}$ \\
\hline Ferromaxx ${ }^{\circledR 7}$ & 90.5 & 7 & 2.5 & - \\
\hline Ferromaxx $^{\circledR} 15$ & 82.5 & 15 & 2.5 & - \\
\hline Ferromaxx ${ }^{\circledR}$ Plus & 68 & 12 & - & 20 \\
\hline Inomaxx ${ }^{\circledR} 2$ & 98 & 2 & - & - \\
\hline Inomaxx ${ }^{\circledR}$ Plus & 63 & 2 & - & 35 \\
\hline
\end{tabular}




\section{RESULTS}

The evaluation of the experiment was carried out by measuring the EWT and SW parameters on the transverse metallographic section of welded structure together with their overall effective height.

Methodology of evaluation parameters EWT, SW and EH shows Figure 7. Figure 8, 9 and $\mathbf{1 0}$ summarise measured data of effective height, of effective wall thickness and surface waviness.

For better representation of results values SW are on the right side of the axis of the sample plotted on the graph at negative values. SW1 represents the values to the left of the sample axis, SW2 to the right of the sample axis.

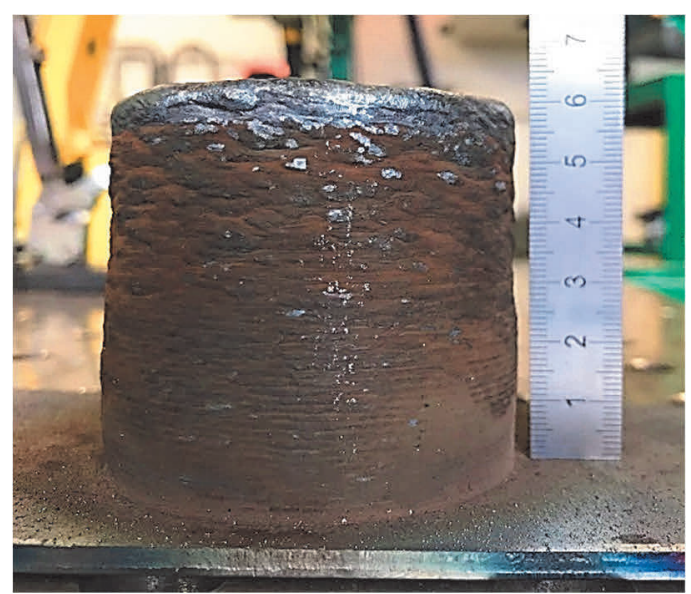

Figure 6 Welded piece
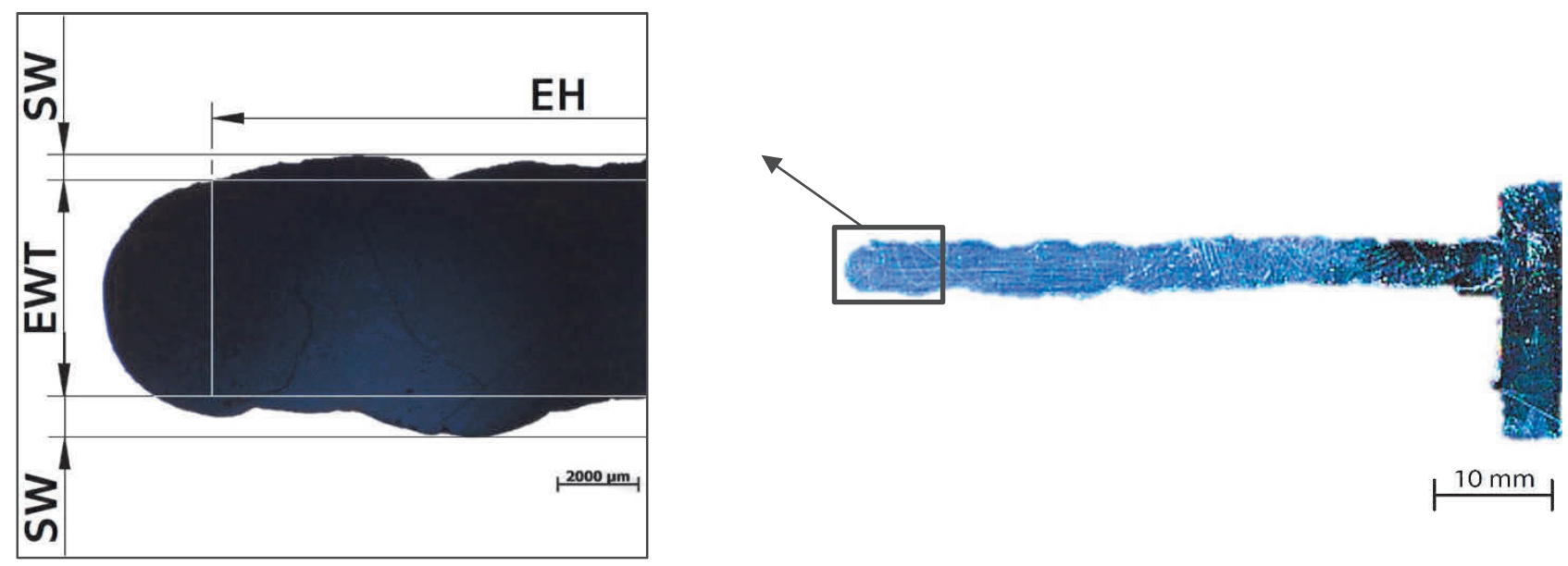

Figure 7 Methodology of evaluation parameters EWT, SW and EH

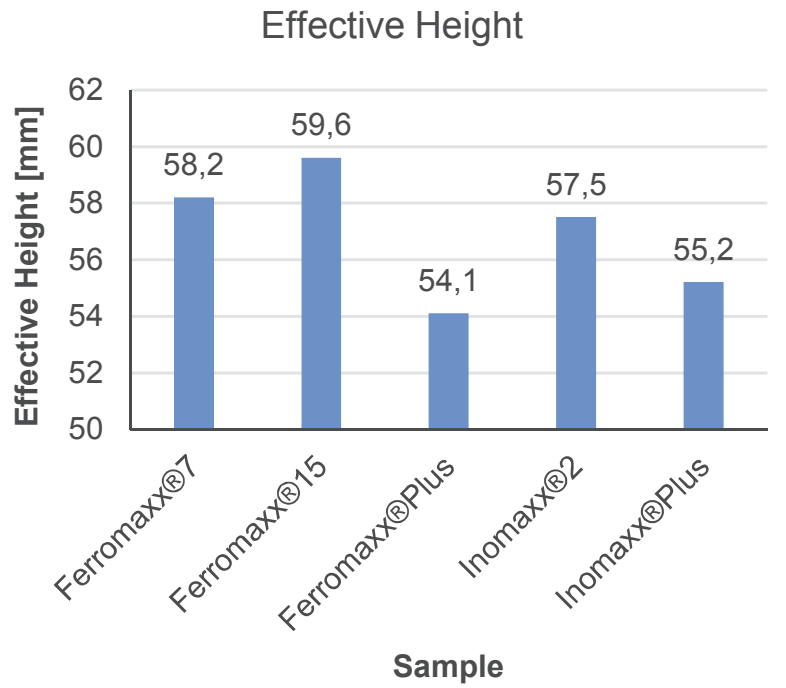

Figure 8 Measured data of Effective Height

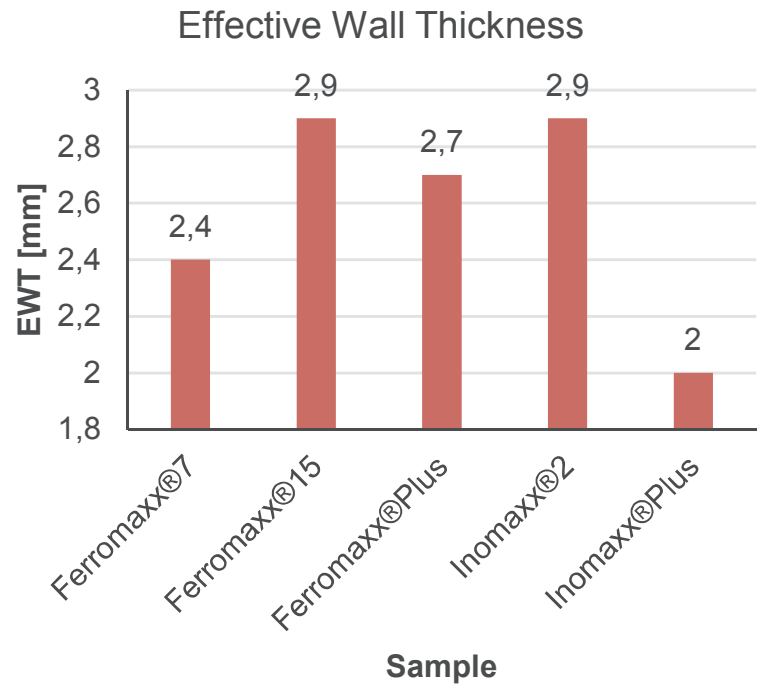

Figure 9 Measured data of Effective Wall Thickness 


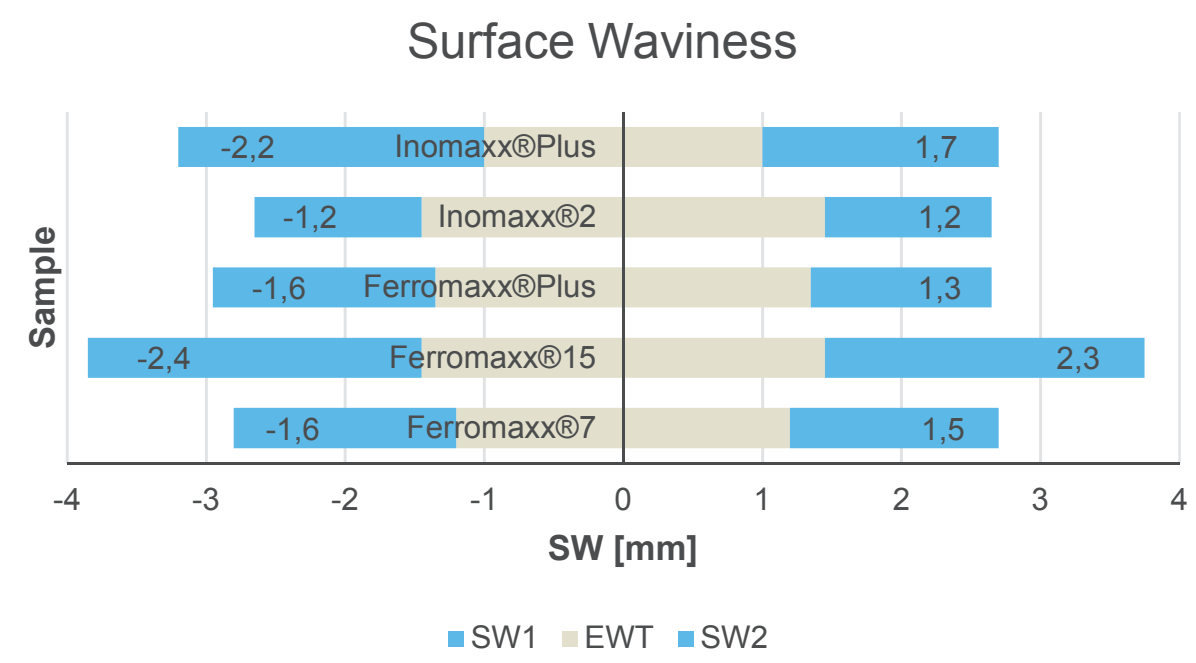

Figure 10 Measured data of Surface Waviness

\section{DISCUSSION}

From the obtained data it can be assumed that the gas with the lowest $\mathrm{CO}_{2}$ content has the lowest thermal conductivity of all used shielding gases. Thus, together with the CMT process, it ensures that the weld does not shrink significantly due to high temperature. The effective wall thickness of the Ferromax ${ }^{\circledR} 15$ shielding gas containing $15 \% \mathrm{CO}_{2}$ is the same as that of the Inomaxx ${ }^{\circledR} 2$ protective gas containing only $2 \% \mathrm{CO}_{2}$. At the same time, it can be observed that by reducing the $\mathrm{CO}_{2}$ content, regular surface waviness has been achieved on both the inner and outer surfaces of the weld even half the value of the Ferromaxx ${ }^{\circledR} 15$ shielding gas. High SW values are also noted for gas containing a lot of helium.

Because of the high thermal conductivity of helium, all measured values are unsatisfactory in terms of material efficiency in terms of the amount of waste material generated when a sample is machined. The high thermal conductivity of helium and $\mathrm{CO}_{2}$ causes geometric deformation of the sample during the welding process and therefore the EWT parameter is rapidly reduced due to the increase in the SW parameter.

Of course, let's not forget that this test was done using a welding wire for structural steels. The results can be different considerably for the use of filler material for high strength steels or stainless steels.

\section{CONCLUSION}

The aim of the experiment was to determine the influence of various shielding gases used in welding on the geometric quality of the structure made by the additive WAAM technology. According to theoretical assumptions about thermal conductivity of used gases, it has been confirmed that the atmosphere with the lowest $\mathrm{CO}_{2}$ and helium content is best suited to the geometric stability of the welded structure from all the shielding gases used.

The experiment helped establish another of the many variables in the process WAAM. Furthermore, it is already possible to monitor the integration of the sensor systems of the robotic device for monitoring the entire process and correcting the movement of the welding torch during the WAAM process.

\section{TERMINOLOGY}

WAAM Wire and Arc Additive Manufacturing

BTF Buy to Fly ratio 


$\begin{array}{ll}\text { EWT } & \text { Effective Wall Thickness } \\ \text { EH } & \text { Effective Height } \\ \text { SW } & \text { Surface Waviness } \\ \text { CMT } & \text { Cold Metal Transfer }\end{array}$

\section{ACKNOWLEDGEMENTS}

\section{Authors acknowledge support from the ESIF, EU Operational Programme Research, Development and Education, and from the Centre of Advanced Aerospace Technology (CZ.02.1.01/0.0/0.0/16_019/0000826), Faculty of Mechanical Engineering, Czech Technical University in Prague.}

\section{REFERENCES}

[1] MARKET RESEARCH REPORT 3D Printing Metal Market Size, Share \& Trends Analysis Report b Form (Filament, Powder), by Product (Steel, Titanium, Nickel), by Application (Medical, Aerospace \& Defense), and Segment Forecasts.1st ed. San Francisco: Global 3D printing machete share, 2018. p. 250.

[2] MCANDREW, A.R., ALVAREZ ROSALES, M. and COLEGROVE, P.a. Interpass rolling of Ti-6Al-4V wire + arc additively manufactured features for microstructural refinement. Additive Manufacturing. 2018. vol 21, no. 5, pp. $340-349$

[3] KOLARIK, L., SUCHANEK, J. and KOLARIKOVA, M. Cladding by method WAAM. MM Industrial Spectrum. 2018. vol. 12 , pp. 60 - 64.

[4] Building large metallic parts with wire arc additive manufacturing. http://www.insidemetaladditivemanufacturing.com/blog/building-large-metallic-parts-with-wire-arc-additivemanufacturing

[5] TUSEK, J. Experimental research of the effect of hydrogen in argon as a shielding gas in arc welding of high-alloy stainless steel. Materials Today. 2018. vol. 5, no. 13, pp. 26990-26996.

[6] KOLARIK, L., KOLARIKOVA, M., VONDROUS, P. and HRABINA, R. The choice of parameters for welding steel S355NL. In DAAAM 2012: 23st International Symposium on Intelligent Manufacturing and Automation. Wien: DAAM, 2012, pp. 1027-1030.

[7] Maxx® Shielding Gases. Air Products. http://www.airproducts.com/Products/Gases/WeldingCutting-Gases/MaxxShielding-Gases.aspx 